\title{
Intercultural experiences from the perspective of narrative interviewing: methodological pitfalls and challenges in the eyes of the student and the teacher
}

\begin{abstract}
This paper attempts to take a critical look at the narrative interview in order to identify the methodological pitfalls and challenges posed by this widely-applied research tool. It analyses the research process in a project involving sixty-four $3^{\text {rd }}$ year students of applied linguistics at a large university in western Poland in the summer term of the academic year 2018/2019. The project included three stages: (1) interviewing a person from another country studying in Poland about their intercultural experiences; (2) transcribing the interviews and (3) presenting the results of their analysis in the form of a written report. On completion of their assignments, the students were asked to share their reflections on all stages of their research in an anonymous survey study. The questionnaire data was juxtaposed with analysis of the student transcripts and reports in order to identify and compare the student and the teacher perspectives on methodological aspects of narrative research. The outcomes of the survey study show that the students, as inexperienced or even first-time researchers, mostly focused on their language proficiency and technical aspects of the interview, while the teacher/researcher pointed primarily to flaws in the formulation of the interview questions and lack of subsequent probing questions, which resulted in superficial responses or even at times deprived the interview of a narrative character. The study also documented the evolution of students as researchers and its results might be applicable for teachers offering courses in academic writing or BA/MA seminars.
\end{abstract}


Keywords: methodology of narrative research, narrative interview, students as researchers, reflective teacher

Słowa kluczowe: metodologia badań narracyjnych, wywiad narracyjny, studenci jako badacze, refleksyjny nauczyciel

\section{Introduction}

In recent years, narrative research has enjoyed considerable popularity in the humanities and social sciences. However, this enthusiasm for the "narrative turn" (Riessman, 1993) has not always been paralleled by a corresponding interest in relevant methods and procedures (Errante, 2000). Thus, addressing the need for further reflection on the application of specific research tools within this approach, the present paper focuses on the narrative interview, which has been successfully used as a qualitative research data gathering tool across disciplines, including applied linguistics and intercultural studies. The main emphasis in this paper is on the methodological aspects of this kind of interview with the aim of identifying typical pitfalls and challenges encountered by narrative researchers. The first part of the paper lays the theoretical foundations of the study which was undertaken and presents the main assumptions of the narrative approach and its use in intercultural studies. It concludes with a discussion of methodological aspects of narrative interviewing. The second part reports the reflections of students participating in a narrative research project, which involved them preparing an interview and transcribing it, and then submitting a written report summarising the main outcomes of the study. The perspective of students as fledgling researchers was then confronted with the evaluation of the students' outcomes by the teacher/researcher coordinating the project with the aim of getting a more informed, profound insight into the application of the narrative interview as a research tool.

\section{The narrative approach}

The term 'narrative' derives from Latin (narratio) and designates a story. Moen (2006: 3) defines a narrative as "a story that tells a sequence of events that is significant for the narrator or her or his audience". Telling stories plays a substantial role in human existence since it helps structure our experiences and make them meaningful. In fact, Polkinghorne (1988) asserts that people are not able to exist without stories and that everybody has a story to tell. Moen (2006: 56) sees life itself as "a narrative inside which we find a number of other stories". 
At the individual level, narratives might act as powerful motivators which provide guidance and inspire change and action: "Stories have the power to direct and change people's lives" (Noddings, 1991: 157). Storytelling also has a social dimension, as apart from producing our own narratives we are also exposed to others' stories (Zellermayer, 1997). In Riessman's view (2008), creating and sharing narratives is a universal phenomenon which surpasses the limitations of space, time, society or age. Stories are potentially interactive as they involve both narrators and listeners and mirror the particular sociocultural and historical context in which they are embedded (Elliot, 2005). From the perspective of sociocultural theory (SCT), the contextual embeddedness of individual stories must be taken into account in their interpretation.

The perception of the narrative as an expression of the self, identity and culture has been made explicit by a number of scholars, in particular sociolinguists (e.g., Coates, 1996; Holmes, Marra, 2005; Cameron, 2003). For instance, Schiffrin (1996) deems narratives "self-portraits", which might be construed simultaneously through the lens of global and local sociocultural norms and individual experience. Cameron (2003: 459) accentuates the significance of transforming an individual's life experience "into a coherent, on-going autobiographical narrative" in gaining a sense of identity in late post-modern times (cf. Wąsikiewicz-Firlej, 2014: 173).

Despite being a relatively new field within the qualitative or interpretive research tradition, interest in the narrative approach has substantially increased in recent years, which is reflected in the growing body of relevant literature. As far as its theoretical foundations are concerned, the narrative approach draws on SCT, Vygotsky's (1978) developmental ideas and Bakhtin's (1986) concepts of dialogism and heteroglossia. Due to the fact that narrative studies primarily aim to investigate human experience, narrative researchers collect and analyse this type of stories (Gudmundsdottir, 2001). This approach enables researchers to study individual accounts of personal experiences and reflections expressed in narratives and organise fragmented chunks into a meaningful whole, reflecting the complexity of life (Elliot, 2005; Riessman, 2008).

Understanding of the narrative approach itself, however, varies among scholars. For example, Moen (2006) asserts that within the qualitative approach "a case study, a biography, a phenomenological or an ethnographic study may have a narrative form of representation" (Moen, 2006: 2; after Cresswell, 1998). Some researchers recognise the narrative approach as a research method (e.g., Connelly, Clandini, 1990; Gudmundsdottir, 2001) though this view is criticised by other scholars, who construe the narrative approach as a frame of reference rather than a method and assume that narratives both reflect and create reality (e.g., Heikkinen, 2002; referred to in Moen, 2006). 
The perspective taken in this paper follows that of Moen (2006: 2), who incorporated all three approaches, categorising the narrative approach as "a frame of reference, a way of reflecting during the entire inquiry process, a research method, and a mode for representing the research study". Therefore, the view slants toward narrative inquiry rather than narrative analysis, since it is not focused on the form of the narrative and the discourse but on the potential of the narrative to "explain and [help us to] understand a phenomenon better" (Swain et al., 2011: xiii). This approach is also in keeping with SCT because of the fact that telling a story not only traces development but also enhances it as the act of telling stories triggers emotions and reflection (Daiute, Lightfoot, 2004).

\section{Narratives in intercultural studies}

The narrative approach has been successfully applied in intercultural studies, enabling researchers to investigate processes of communication and intercultural cooperation, especially in multinational organisations (e.g., Czarniawska, Gagliardi, 2003; Søderberg, 2006; Gersten, Søderberg, 2010, 2011; Weick et. al., 2005). Narrations have cognitive, semantic and explanatory functions (Wilczewski, Søderberg, 2017: 555) since they enable communication participants to understand, give meaning to and interpret the reality they experience in intercultural contexts. For the researcher, narratives facilitate the identification of both differences and similarities in intercultural experience, which might lay the foundations for effective communication and mutual trust as well as lead to the development of cultural intelligence and intercultural competence (Søderberg, Worm, 2011: 58). Based on the analysis of narrative interviews with Chinese and western managers working in Chinese subsidiaries of global companies, Søderberg and Worm (2011) illustrated the potential of the narrative approach in scrutinising intercultural communication, surpassing the limitations of interpreting cultural phenomena through clearly defined cultural patterns (e.g., the dichotomous categorisation of low-versus high-context cultures or individualist versus collectivist cultures). As the authors argue, the clear-cut boundaries of cultural patterns do not apply to expats who often share a range of multicultural experiences gained in various educational and professional settings, and who are typically at least bilingual and aware of the cultures of both their native and the host country.

Apart from providing valuable research data, a narrative interview also has a lot to offer the narrator. As Søderberg and Worm (2011) observe, participation in a narrative interview instigates the narrator to reflect on intercultural experiences by activating higher-level thinking and metacognition. In fact, metacognition is recognised as a critical element in intercultural learning 
(Gertsen, Søderberg, 2010: 256). For this reason, the narrative method might have a practical application in the development of cultural intelligence within corporations. This could take the form of storytelling by expats, enabling them to express themselves, articulate their needs and share their intercultural experiences in order to reflect on them, understand them and give them new meaning (ibid.).

\section{Methodological aspects of narrative interviewing}

One of the most distinctive features of narrative research is the collaborative, dialogic nature of the relationship between the researcher and the research subject (Moen, 2006: 60). For this reason, in the context of narrative research, Moen (ibid.) advocates the use of the term "subject" or, alternatively, "collaborator" or "participant", rather than "informant". Building such a relationship between the researcher and narrator requires adequate time and space, making both parties comfortable (cf. Connelly, Clandini, 1990; Heikkinen, 2002) as well as offering a sense of a non-judgmental attitude and equality (Fetterman, 1998).

Although various data collection methods might be used within narrative research, for example: notes, journal records, observations, letter writing, autobiographical writing etc. (Connelly, Clandini, 1990), this paper focuses on the narrative interview. Compared to other types of interviews, the narrative interview is the least structured and it primarily aims to generate stories that provide an insight into individuals' lives and experiences. In the view of Lofland and his colleagues (2006: 76), it provides "rich, detailed materials that can be used in qualitative analysis" and "[i]ts objective is to find out what kind of things are happening rather than to determine the frequency of predetermined kinds of things that the researcher already believes can happen". In an unstructured, narrative interview the researcher is not expected to collect answers to a list of questions but rather to elicit a story (Karch, 2017). Thus, in contrast to semi-structured interviews, fewer questions are asked to set the scene and the interviewer mostly listens to or asks clarifying or probing questions. The questions should be phrased as open-ended. By asking follow-up questions, the researcher might encourage the interviewee to elaborate on the story and share their emotions and evaluations, which leads to "soliciting a rich and well developed narrative" (Karch, 2017: 1073). Søderberg (2006: 402) also advises narrative researchers to refrain from comments and evaluations in the course of the interview.

Taking into account the specific relationship between researchers and participants in narrative research, interviewers must be particularly skilled in building rapport by being attentive, respectful to the subject and authentically interested in the story being narrated, which might be communicated both verbally and nonverbally (Karch, 2017: 1073). In fact, in this type of interview 
the interviewee becomes the narrator while the researcher takes on the role of listener, facilitator of the interaction or as Søderberg (2006: 402) puts it "the narrator's empathic 'fellow traveller' (Gabriel, 2000)".

Additional challenges are faced when the researcher is interviewing representatives of other cultures. Beszterda (2016) points to a number of cultural pitfalls in such a situation, which are listed below:

- over-confidence of the researcher in assuming the uniformity of European cultures and universality of experiences,

- the transculturality of migrant interviewees and related difficulties in the recognition of the individual's cultural hybridisation,

- knowledge of language and cultural contexts,

- the ambiguity of utterances,

- the necessity to negotiate meanings (Beszterda, 2016: 86-90).

Apart from cultural pitfalls, Beszterda (2016: 90-96) also enumerates a range of methodological pitfalls that are not directly related to the cultural dimensions of the interviewing process and, in fact, might pertain to any type of interview. First and foremost, Beszterda (2016) emphasises the time limitations of specific interviews, the consequences of which might be mitigated by meticulous preparation for the interview, including thoroughly researching the issues to be discussed as well as getting as much information about the interviewee as possible. Secondly, the language of the interview must be adapted to the cognitive capabilities of the interviewee. This also involves the wording of questions, such as, for example, avoiding leading or ambiguous questions. This is thoroughly discussed in the literature on the methodology of research (e.g., Patton, 2002; Dörnyei, 2007). Beszterda (2016) also notes that researchers tend to simplify linguistic forms, which might result in unnecessary familiarity, thus affecting the neutrality of the researcher-narrator relationship. Finally, there are other difficulties pertaining to the reliability and accuracy of interview transcription and the maintenance of the researcher's attention.

\section{Research design}

The study undertaken aimed to analyse the methodological aspects of narrative interviews with representatives of other cultures conducted by a group of inexperienced researchers (undergraduate students) as a part of the requirements for one of their university courses in spring 2019. After the submission of their papers and interview transcripts, the students were asked to express their reflections on all the stages of the research process in written form. Two research questions (RQ) were posed in the study: 
RQ1: What kind of methodological pitfalls were encountered by the students while conducting their narrative research?

RQ2: What kind of methodological pitfalls were identified by the teacher coordinating the narrative research?

The participants in the study were $3^{\text {rd }}$ year students $(n=64)$ of applied linguistics at a large university in western Poland in the academic year 2018/19 whose names are not given for the sake of confidentiality (the participants have been coded with numbers).

The research took a mixed-method approach and was designed in two stages which correspond to the two research questions posed. The research tool used to address RQ1, i.e. to elicit the students' reflections on their narrative research project completed, was a questionnaire which contained 3 major openended questions accompanied by 6 sub-questions and 2 closed-ended questions.

In order to address RQ2, the teacher meticulously examined the whole corpus of 24 interview transcripts and research reports, submitted by students as their final pair-work or three-person team projects. In more detail, the project involved conducting a narrative interview with a person from another country studying in Poland, transcribing it and interpreting the data in the form of a written report. A homogenous sampling strategy was applied to select interviewees sharing similar experience, i.e. participation in a study-abroad programme in Poland (cf. Dörnyei, 2007: 127). Individual interviews were conducted in English that was, with 2 exceptions, a non-native language to both the interviewers and interviewees. They lasted from a minimum of 6.53 minutes to a maximum of 32.52 minutes (median 16 minutes). The interviews were transcribed verbatim in accordance with simplified transcription conventions developed by Boje (1991). The teacher first analysed and evaluated the materials provided by students, paying special heed to students' interviewing skills, and then proceeded to identification and categorisation of categorised methodological traps. The results of this qualitative analysis were juxtaposed with the data obtained from the survey (52 questionnaires in total; return rate: $81 \%$ ).

\section{Results and discussion}

The results of the study will be presented in two subsequent subsections addressing RQ1 and RQ2 respectively. Thus, subsection 6.1 will report on the data obtained from the questionnaire while section 6.2 will present the teacher's reflections, based on the analysis of the corpus of student interview transcripts and reports, juxtaposing them with the questionnaire results in order to compare the perspectives of the student, the inexperienced researcher, 
and the teacher, the experienced researcher. The textual organisation of the analysis reflects the layout of the questionnaire which was used.

\subsection{Students' reflections on the research undertaken}

Question 1: What did you find most difficult when carrying out your research project in the following stages:

a. Preparing the interview

At this stage of the project the majority of the students reported some problems, yet no difficulties were experienced by 18 students. Generally, the responses were rather consistent as only 4 commonly shared problems were identified. First of all, most students ( $n=24)$ encountered some problems finding an appropriate respondent - a person from another country studying in Poland. Another challenge was fixing a date convenient for both parties $(n=13)$ or finding an appropriate place to conduct the interview $(n=6)$. Finally, 2 respondents pointed to difficulties getting motivated.

b. Conducting the interview

Only 10 students claimed that they did not face any difficulties while conducting the interviews, yet some isolated voices sounded very enthusiastic. For example,

[t]hat was definitely the most interesting part of the interview. From the very beginning, it was clear for my interlocutor that I wanted him to speak as much as possible. He told me a lot of interesting stories, anecdotes, which seem to be essential for this type of study. Additionally, his language skills enabled us to communicate effectively. I did not run into any serious difficulties (S40).

The majority, however, experienced a whole range of problems, which have been categorised into four areas, i.e.: language problems $(n=19)$, communication/emotional problems $(n=15)$, technical problems $(n=13)$ and miscellaneous, e.g., poor interviewing skills $(n=3)$.

\section{Language problems}

For some students $(n=10)$, it was an eye-opening experience as it made them realise how many language mistakes they had made. In fact, they had not been aware of them until they started transcribing the interviews they had conducted. Five students found it difficult to ask questions in a simple and clear way or paraphrase them. Some complaints concerning the respondent's poor competence in English 
were also identified $(n=4)$. As one of the students noted (S27), her respondent did not really understand her questions. Poor pronunciation or a heavy accent also hindered communication and led to some misunderstandings. For instance, "my respondent pronounced she like si" (S17).

\section{Communication problems}

As regards problems related to communication or emotion management, some student collaborators mentioned being stressed out $(n=2)$ and tense $(n=2)$, due to being unfamiliar with the respondent and consequently felt discomfort and were unable to create a relaxed atmosphere $(n=2)$. Among other problems, students also pointed to poor contact with the respondent $(n=2)$ and the fear of being misunderstood $(n=2)$. They also complained about the shyness and tension of their respondents $(n=2)$ or their unwillingness to produce longer utterances $(n=1)$. Thus, it might be concluded that for some students interviewing a stranger was seen as a stressful experience that was outside their comfort zone.

\section{Technical problems}

Technical problems were mostly related to finding a suitable, quiet place $(n=4)$ or getting access to appropriate recording equipment $(n=3)$. In several cases there were problems with recording the session $(n=6)$ and in 3 of these cases the interviews needed to be repeated.

\section{Miscellaneous}

Finally, 3 students expressed their concerns related to the insufficient length of the interviews $(n=1)$, interrupting the interviewee $(n=1)$ and going off topic $(n=1)$.

\section{c. Transcription}

Despite the fact that simplified transcription conventions were used in the study (Boje, 1991), for the majority of the students, this stage of the research project appeared to be the most challenging, though 4 individuals reported absolutely no problems. Thus, for some it was "the most pleasant" while for others the "most difficult" part of the project. The problems reported might be grouped into 3 major categories, labelled "problems with understanding", "problems related to the process of transcription", "problems related to the quality of the recording", and a fourth category of "miscellaneous problems".

\section{Problems with understanding}

Over half of the students reported problems with recognising single words in their interviewees' utterances $(n=27)$. Understanding and ultimately 
transcribing were hindered by the interviewee's pronunciation $(n=7)$, the rapid pace of their utterances $(n=5)$, unnecessary fillers and pauses $(n=2)$ as well as language mistakes $(n=1)$. As one of the participants (\$40) summarised it: "Not all of the utterances or words were comprehensible. The pace was pretty fast, which made the transcription process really challenging. Additionally, it was my first transcription and I was not really quite sure what kind of symbols I was expected to use in a given situation".

\section{Problems related to the process of transcription}

The majority of the participants had no previous experience with transcribing interviews and their lack of experience was identified as a serious limitation. Despite having been given clear instructions and detailed transcription guidelines, the students were still unsure what kind of transcription symbols they were supposed to use or how they should mark the length of the pauses or overlapping speech $(n=6)$. There were also doubts about the transcription of stammering and grammatical mistakes $(n=2)$.

\section{Problems related to the quality of the recording}

The students also noted that the process of transcribing their interviews was, to a great extent, affected by the quality of the recordings. Therefore, noise, mostly resulting from the inappropriate selection of the interview venue, was singled out as the most significant distractor $(n=9)$ which seriously hindered their work. The poor quality of the recordings was also a result of inappropriate seating arrangements and locating the respondent far from the microphone of the recording device. These flaws sometimes led to linguistic misunderstandings. For example, "I was just mmm... hanging out with my friends" initially sounded like "I was just making out with my friends" (S7).

\section{Miscellaneous problems}

Finally, some students $(n=7)$ complained about the workload related to the necessity of tedious, multiple replaying of interviews as well as problems with concentration $(n=2)$.

d. Producing the final report

Surprisingly, this stage of the project was found to be completely unproblematic by 17 students. Additionally, 5 of them emphasised the great value of teamwork, which was found to be very helpful. The majority of the problems reported concerned academic language $(n=16)$, 
especially its lexis, form and register. Students highlighted their lack of experience in this respect. Another problematic area was the analysis and interpretation of data $(n=15)$. Finally, 7 students had problems with drawing conclusions and formulating their reflections and one found it difficult to summarise longer text passages.

Question 2: Did you make any mistakes while conducting the interview? In response to this question, almost one-third of the students surveyed $(n=18)$ pointed to language mistakes. Seven respondents mentioned technical problems (e.g., inappropriate selection of the venue, recorder or placement of the equipment). The other most common problems involved interrupting the respondent $(n=5)$, managing stress $(n=5)$ and going off topic $(n=3)$. Some individuals indicated being chaotic $(n=2)$ and getting lost with the questions $(n=2)$.

a. What could you have done better?

In general, the respondents identified several aspects of the interview that, in their opinion, could have been conducted in a better way, which included: asking more questions $(n=6)$, better preparation of the questions $(n=4)$, breaking the ice with the respondent/a longer warm-up $(n=3)$, reacting to the responses rather than focusing on asking questions $(n=2)$, being more inquisitive and precise $(n=3)$, being less expressive $(n=2)$.

b. Which aspects of the interview are you most satisfied with?

Overall satisfaction with the interview was expressed by the majority of the students $(n=34)$, who treated it as an interesting and enlightening experience $(n=9)$. The participants were particularly satisfied with the simply getting to know the respondent and having an insight into their feelings and experiences $(n=10)$. Some also pointed to the appropriate selection of the respondent $(n=5)$ and establishing a good rapport $(n=4)$. The students also appreciated their respondents' genuine interest in the project as well as their engagement and willingness to cooperate $(n=6)$. Finally, the interviewees expressed their own involvement in the project $(n=5)$, which might be summarised with the following words: "I simply did my best" (S37).

Question 3: While conducting an interview in the future, I will pay particular attention to...

In the next section of the questionnaire, the students were asked to declare which aspects of the interview they would want to improve in the future. They formulated over 70 individual reflections, which have been grouped into the predominant categories presented below: 
- accuracy and clarity of the questions asked to avoid ambiguity ( $n=24)$,

- time and venue of the interview, placement of the recording equipment/better quality $(n=14)$,

- language competence (fluency, accuracy, pronunciation) ( $n=12)$,

- better linguistic and factual preparation $(n=11)$,

- better interaction with the respondent $(n=7)$,

- being more responsive $(n=7)$,

- not interrupting the respondent $(n=5)$,

- being less expressive $(n=3)$,

- selecting a competent respondent $(n=3)$,

- being more engaged $(n=2)$,

- the respondent's pace of speech $(n=2)$,

- being focused $(n=2)$,

- length of the interview $(n=2)$,

- every aspect of the interview $(n=2)$.

\section{Questions 4 and 5}

The final two questions were closed-ended and were aimed at investigating the students' overall perception of their participation in the project in terms of its usefulness and educational value. The respondents agreed with the statement that the research project undertaken had helped them to develop their research skills (median 4 on a 5 point Likert scale where 5 stood for "I completely agree" and 1 for "I don't agree at all". The overall participation in the project was deemed useful (median 4.2 on a 5 point Likert scale where 5 stood for "useful" and 1 for "useless".

\subsection{The teacher's perspective}

The teacher's evaluation of the students' performance in the project was based on the recorded interviews, their transcripts and the students' written reports. Even though the teacher's and students' perspectives were to a large extent similar (e.g., language competence), in some selected areas the difficulties identified did not overlap. What is more, in some cases the importance of certain challenges was accentuated differently. The students actually tended to focus on the form and language of the interview rather than the content and quality of the responses. They also expressed concern over technical and organisational difficulties. These problems, among others, were also identified by the teacher. The transcripts clearly pointed to apparent deficits in English language competence and the problems identified concerned almost every 
aspect of language use, i.e. grammar, vocabulary, pronunciation, fluency, register, etc. The number of language mistakes was even surprising to the students who had been completely unaware of them until they started to transcribe the recorded interviews. Although in the teacher's view the language problems were apparent, they did not stand out from other difficulties.

Primarily, the major problems pertained to the formulation and handling of the questions. Despite prior training on interviewing techniques, most students, at least occasionally, failed to avoid close-ended questions, which resulted in rather laconic, superficial responses, as illustrated in Extract 1. $\mathrm{Yes} / \mathrm{No}$ answers seemed to hinder further interaction and added to the feeling of discomfort and stress for both the interviewer and the interviewee. In some cases, this led to the data obtained being of poor quality or to interruption or shortening of the interview, which is evidenced by the disparity in the duration of individual interviews, varying from 6.53 to 32.52 minutes. In the interview transcripts, the interviewer is coded as ' $I$ ' and the interviewee as ' $R$ '.

\section{Extract 1. Close-ended questions}

107 I: (yhm) (3.0) and do you feel that you belong to any cultural group?

108 You know your cultural identity.

109 R: [Coughing] Yes.

110 I: To Colombia right?

111 R: To Colombia.

112 I: And do you feel that you identify now after these two months with

113 Poland?

114 R: No.

115 I: No //it's//

$116 \mathrm{R}: / / \mathrm{No} / / \mathrm{I}$ 'm still Colombian.

117 I: Okay [Laughing] (I1)

By contrast, several students could be placed at the other end of the scale, because they treated the interview as a social occasion, which enabled them to share rather irrelevant and lengthy comments. As a result, in some cases the whole conversation went completely off topic, as might be illustrated by Extract 2 below.

\section{Extract 2. Going off topic}

56 I1: And let me ask you, this is question out of, out of this group of

57 question (...)

58 R: Yeah (...)

59 I1: Let me ask you, what is in this paper? I'm just interested cause

60 you know, last five years our history is still changing, I mean some 
61 facts are going out let's say, cause you know we used to believe that

62 Solidarity movement was the best thing we could ever met ever in our

63 history but now there are some facts and it's now so pure and not as

64 perfect as it was.

65 R: Well, I don't really know, because I haven't really research the

66 topic but it was like a decade in which the structure in Poland

67 changed from communism to democracy (...)

68 I1: Yeah, mhm

69 R: So it's obviously something very important and from where I could

70 read about it, it's pretty big deal. I don't know anything about (...)

71 I1: No, no. I'm just curious, what they say you had to read.

72 R: No, no, I'm finding the reading myself.

73 I1: Oh, Ok, so that's perfect, that's perfect. So next question

74 is... What was the type and length of your previous stays abroad? (I17)

The above extract also illustrates the violation of one the basic principles of the methodology of conducting interviews formulated by Robson (2002: 274): "Listen more than you speak. Most interviewers talk too much. The interview is not a platform for the interviewer's personal experiences and opinions". Refraining from comments and evaluations in the course of the interview is also recommended by Søderberg (2006: 402).

In the teacher's opinion, the students' inappropriate handling of the questions might to a great extent be accounted for by insufficient preparation. Equipped with an interview protocol and having been thoroughly instructed in the methodology of narrative interviews in class, the majority of the students took their interviewing skills for granted and did not prepare enough for their task. This was particularly visible in the handling of the question concerning cultural identity. A number of students did not give this question enough consideration so when asked by the respondents to clarify it, they were confused and unable to paraphrase it, as shown in Extract 3 below.

\section{Extract 3. Cultural identity}

78 I: That's interesting, I'm just curious of this country, by the way

79 my mother teaches geography and I have to know all this countries in

80 Europe and all over the World. And it's yeah, just interesting. Ok so

81 if it's your first stay abroad so what was your cultural identity

82 profile?

83 R:(2.0) what? Can u?

84 I: I don't understand this question too (laughing). What was your

85 cultural identity profile... so maybe it's about where are u from, I

86 don't know if it's question about the religion but it's a culture

87 yeah so (...) 
88 R: Yeah, so my ethnic identity is Albanian.

89 I: Mhm

90 R: I, like, the majority of population in my country is Muslims. I

91 was brought up as Muslim, but now I'm an atheist. What else could I

92 say?

93 I: I think that's enough (laughing) (I17; emphasis mine)

Apart from the lack of preparation, Extract 3 also illustrates that the interviewer lacks the cultural sensitivity that is expected of an intercultural researcher (cf. Beszterda, 2016: 86-90).

Another problem was the formulation of long, complex questions, asking about more than one thing at once (cf. Dörnyei, 2007). Even though the students were specifically instructed in this and were requested to adapt the items listed in the protocol (possible problem areas for the interviewees), some of them simply read them in one go (see Extract 4).

\section{Extract 4. Complex questions}

61 I: Okay, thank you very much. A second question. Do you face

62 challenges in your foreign environment related to your daily

63 functioning? If yes, in which areas? Is it about accommodation,

64 transportation... medical care? What are the most challenging... aspects

65 for you? (I5)

In consequence, the interviewees had problems processing and remembering complex, lengthy questions, which translated into very laconic, superficial and incomplete replies. Generally, it might be stated that most interviewers were not very curious or motivated to get more precise, detailed information. Most of them failed to probe, i.e. ask follow-up questions for detail and clarification (see Dörnyei, 2007: 138), and did not encourage their interviewees to elaborate on specific items. As illustrated by Extract 5 and Extract 1 (especially lines 116-117), the interviewers simply accepted the replies given and immediately moved on to the next question in their protocol rather than elicit a story (cf. Karch, 2017; Lofland et al., 2006).

\section{Extract 5. No follow-up questions}

90 I: okay so ... so ... were the challenges related to your

91 language competence in Polish

92 R: yes hahaha of course

93 I: sorry 'bout that

94 and so ... also do you face challenges in your studies at

95 the foreign university

96 R: no, not at all (I11) 
All in all, encouraging elaboration might be considered as a commonly shared weakness among the interviewers since the use of effective probing techniques, including "silent probes", "echo probes" or "low-interference paraphrasing or reflective summary and clarification questions" (Dörnyei, 2007: 140) was rarely identified.

Finally, the students should have paid more attention to the opening of the interview to build rapport with their interviewees in order to create an atmosphere of mutual friendliness and trust. Since most of the participants were rather inexperienced researchers, a more elaborate introduction would help both parties to overcome stress and become more focused. Extract 6 illustrates how the interviewer proceeded to ask questions after a very short introduction:

\section{Extract 6. Abrupt introduction}

1 I: Hello, ee thank you for coming. So we can start with the first

2 question. How well were you prepared for ee to your stay abroad? (I8)

As a result, the respondent felt a bit confused and asked the interviewee to repeat her question. Moreover, the beginning of the interview was rather inefficient as the interviewee was definitely out of breath after her recent arrival at the venue. In fact, both parties had problems with fluency, made numerous pauses and used gap-fillers. Additionally, the importance of the opening of the interview must not be ignored since "this is the time when we set the tone/ climate of the interview and (...) establish our credentials and make ourselves accepted" (Dörnyei, 2007: 139-140). Demonstrating our interest in the interviewee's replies and facilitating a relaxed, comfortable atmosphere help to build good rapport with the interviewee, increasing the probability of obtaining honest and detailed responses (cf. Connelly, Clandini, 1990; Heikkinen, 2002).

\section{Conclusions and implications}

The study pointed to a number of typical methodological pitfalls and challenges encountered by the students. First of all, as inexperienced researchers, the students faced difficulties at basically all stages of the research project, which included selecting appropriate respondents, arranging the interview and conducting it, preparing the transcription and producing the final report. While sharing their reflections on their experience as researchers, the students primarily focused on their lack of language competence in English and the number of various language mistakes they made. They also paid a lot of attention to technical and organisational problems as well as noted that they needed better preparation for the interview and to build rapport with 
the interviewee. Some of them also realised that their interviewing skills particularly asking probing questions - needed significant improvement.

What comes to the fore in the teacher's view is the lack of appropriate interviewing skills rather than language competence. This was seen as the major limitation of the study, as it possibly affected the quality of the data obtained. The interviewers had difficulties with asking probing questions, getting more detailed responses, or with paraphrasing questions that were not understood. They tended to cling to the protocol and did not encourage their respondents to elaborate on relevant issues. Instead, some of them asked complex questions and did not bother to paraphrase them, explain misunderstandings or insist on obtaining complete, relevant answers. In most cases, even Yes/No answers failed to evoke any reaction on the part of the interviewers or motivate them to ask follow-up questions. Contrary to Beszterda's (2016: 87) recommendations, the students failed to negotiate meanings or clarify ambiguities, even though neither the interviewers nor the interviewees (with two exceptions) were native speakers of English (the language of the interview). For this reason, some parts of the interviews could be qualified as semi-structured rather than truly narrative.

Moreover, in numerous cases, the interviewers played too active a role in the interview: they dropped various unnecessary or irrelevant comments, used too many repetitions; some even shared their own stories, went off topic to discuss issues that were of their own personal interest or simply interrupted the interviewee. Most students were inexperienced in managing the interviewer-interviewee relationship: they either kept their distance or became overly familiar with their respondents, treating their project as a social occasion. This was also seen in the colloquial language used and in the differing lengths of the interviews, which were often too brief or too chatty. Finally, on the whole the interviewers did not make much effort to prepare for the interview either practically or theoretically, which should be top priority for the researcher (cf. Beszterda, 2016: 87).

Despite numerous difficulties, participation in the project was definitely an eye-opening experience for the students. Acting as researchers, the students realised the importance of preparing for an interview, which should include the selection of a suitable respondent, venue, and equipment as well as acquainting themselves with the interview questions, making sure that they understand them and can make them comprehensible for their respondents. The interviewers also saw how stress affects both the interviewee and the interviewer and realised that ensuring the respondent's emotional comfort made for a higher quality interview. Moreover, preparing the transcription and the final report enabled the students to become aware of their own performance, 
especially the mistakes they made with language, and their problems with formulating and asking questions. They could also recognise difficulties in relationship management or lack of insight. Even though the students were provided with detailed instructions on the methodology of narrative research, it was in fact their own hands-on experience which allowed them to understand their role in the research process and the effect of this on the final outcome.

Finally, the study undertaken has pedagogical application. First of all, it documented the process of the students' growth from fledgling researchers to more reflective practitioners. It also clearly pointed out the most challenging aspects of narrative interview-based research for the students and offered authentic transcripts and reports that might be successfully used in the classroom. All in all, the joint project turned out to be an invaluable experience, contributing to the professional self-development of both the student and the teacher.

\section{BIBLIOGRAPHY}

Bakhtin M. (1986), The problem of speech genres, (in:) Emerson C., Holquist M. (eds.), Speech genres and other late essays. Austin: University of Texas Press, pp. 60-102.

Beszterda R. (2016), Pułapki wywiadu w badaniach biograficznych. Doświadczenia etnologiczne, (in:) Piorunek M. (ed.), Badania biograficzne i narracyjne w perspektywie interdyscyplinarnej. Aplikacje-egzemplifikacje-dylematy metodologiczne. Poznań: Wydawnictwo Naukowe UAM, pp. 85-97.

Boje D.M. (1991), The storytelling organization: A study of story performance in an office-supply firm. "Administrative Science Quarterly", No 36(1), pp. 106-126. Cameron L. (2003), Metaphor in educational discourse. London: Continuum. Coates J. (1996), Women talk. Oxford: Blackwell.

Connelly F.M., Clandini D.J. (1990), Stories of experience and narrative inquiry. "Educational Researcher", No 19(5), pp. 2-14.

Cresswell J.W. (1998), Qualitative inquiry and research design: Choosing among five traditions. London: Sage.

Czarniawska B., Gagliardi P. (eds.) (2003), Narratives we organize by. Amsterdam: John Benjamins.

Daiute C., Lightfoot C. (eds.) (2004), Narrative analysis: Studying the development of individuals in society. Thousand Oaks, CA: Sage Publications.

Dörnyei Z. (2007), Research methods in applied linguistics. Oxford: Oxford University Press.

Elliot J. (2005), Using narrative in social research. Qualitative and quantitative approaches. London: Sage Publications. 
Errante A. (2000), But sometimes you're not part of the story: Oral histories and ways of remembering and telling. "Educational Researcher", No 29(2), pp. 16-27.

Fetterman D. (1998), Ethnography: Step by step. Newbury Park, CA: Sage.

Gabriel Y. (2000), Storytelling in organizations: Facts, fictions, and fantasies. Oxford: Oxford University Press.

Gertsen M.C., Søderberg A.-M. (2010), Expatriate stories about cultural encounters: A narrative approach to cultural learning processes in multinational companies. "Scandinavian Journal of Management", No 26, pp. 248-257. Gertsen M.C., Søderberg A.-M. (2011), Intercultural collaboration stories: On narrative inquiry and analysis as tools for research in international business. "Journal of International Business Studies", No 42(6), pp. 787-804. Gudmundsdottir S. (2001), Narrative research on school practice, (in:) Richardson V. (ed.), Handbook of research on teaching. Washington: American Educational Research Association, pp. 226-240.

Heikkinen H.L.T. (2002), Whatever is narrative research? (in:) Huttunen R., Heikkinen H.L.T., Syrjälä L. (eds.), Narrative research: Voices of teachers and philosophers. Jyväskylä: SoPhi, pp. 13-28.

Holmes J., Marra M. (2005), Narrative and the construction of professional identity: The workplace, (in:) Thornborrow J., Coates J. (eds.), The sociolinguistics of narrative. Amsterdam: Benjamins, pp. 191-213.

Karch F. (2017). Narrative interviewing, (in:) M. Allen (ed.), The SAGE encyclopedia of communication research methods. Thousand Oaks: SAGE Publications, Inc., pp. 1073-1075.

Lofland J. et al. (2006), Analyzing social settings: A guide to qualitative observation and analysis. Belmont, CA: Wadsworth/Thomson Learning.

Moen T. (2006), Reflections on the narrative research approach. "International Journal of Qualitative Methods", No 5(4), pp. 56-69.

Noddings N., (1991). Stories in dialogue: Interpersonal reasoning, (in:) Witherell C, Noddings N. (eds.). Stories lives tell: Narrative and dialogue in education. New York: Teachers College Press, pp. 157-170.

Patton M.Q. (2002), Qualitative research and evaluation methods. Thousand Oaks, CA: Sage.

Polkinghorne D.E. (1988), Narrative knowing and the human sciences. Albany, NY: State University of New York Press.

Riessman C.K. (1993), Narrative analysis. Newbury Park, CA Sage.

Riessman C.K. (2008), Narrative methods for the human sciences. Newbury Park, CA: Sage.

Robson C. (2002), Real world research: A resource for social scientists and practitioner-researchers. Oxford: Blackwell. 
Schiffrin D. (1996), Narrative as a self portrait. Sociolinguistic construction of identity. "Language in Society", No 25(2), pp. 167-203.

Søderberg A.-M. (2006), Narrative interviewing and narrative analysis in a study of a cross-border merger. "Management International Review", No 46(4), pp. 397-416.

Søderberg A.-M., Worm V. D. (2011), Communication and collaboration in subsidiaries in China: Chinese and expatriate accounts. "European Journal of Cross-Cultural Competence and Management", No 2(1), pp. 54-76.

Swain M., Kinnear P., Steinman L. (2011), Sociocultural theory in second language education. Bristol-Buffalo-Toronto: Multilingual Matters.

Vygotsky L.S. (1978), Mind in society: The development of higher psychological processes. Cambridge, MA: Harvard University Press.

Wąsikiewicz-Firlej E. (2014), Constructing the professional identity of EFL teachers through languaging: A narrative inquiry, (in:) Lankiewicz, H., WąsikiewiczFirlej, E. (eds.), Languaging experiences: Learning and teaching revisited. Newcastle upon Tyne: Cambridge Scholars Publishing, pp. 157-190.

Weick K.E., Sutcliffe K.M., Obstfeld D. (2005), Organizing and the process of sensemaking. Organization Science", No 16(4), pp. 409-421.

Wilczewski M., Søderberg A-M. (2017), Badania nad komunikacja międzykulturowa: Dotychczasowe paradygmaty i perspektywy badawcze. „Zeszyty Prasoznawcze", No 3(231), pp. 540-566.

Zellermayer M. (1997), When we talk about collaborative curriculum-making, what are we talking about? "Curriculum Inquiry", No 27(2), pp. 187-214. 